\title{
YeiL, the third member of the CRP-FNR family in Escherichia coli
}

\author{
Muna F. Anjum, Jeffrey Green and John R. Guest
}

The Krebs Institute for Biomolecular Research, Department of Molecular Biology and

Biotechnology, University of Sheffield, Western Bank, Sheffield S10 2TN UK
Author for correspondence: John R. Guest. Tel: +44 114222 4406. Fax:. +44 1142728697 e-mail: j.r.guest@sheffield.ac.uk

The yeiL open reading frame located at $48.5 \mathrm{~min}(2254 \mathrm{~kb})$ in the $n$ fo-fruA region of the Escherichia coli chromosome was predicted to encode a CRP and FNR paralogue capable of forming inter- or intra-molecular disulphide bonds and incorporating one iron-sulphur centre per 25 kDa subunit. Purified MBP-YeiL (a maltose-binding-protein-YeiL fusion protein) was a highmolecular-mass oligomer or aggregate which released unstable monomers (68 kDa) under reducing conditions. The MBP-YeiL protein contained substoichiometric amounts of iron and acid-labile sulphide, and an average of one disulphide bond per monomer. The iron and sulphide contents increased consistent with the acquisition of one [4Fe-4S] cluster per monomer after anaerobic NifS-catalysed reconstitution. By analogy with FNR and FLP (the FNRlike protein of Lactobacillus casei) it was suggested that the transcriptionregulatory activity of YeiL might be modulated by a sensory iron-sulphur cluster and/or by reversible disulphide bond formation. A yeiL-lacz transcriptional fusion showed that aerobic yeiL expression increases at least sixfold during stationary phase, requires RpoS, and is positively autoregulated by YeiL, positively activated by Lrp (and IHF in the absence of FNR) and negatively regulated by FNR. A regulatory link between the synthesis of YeiK (a potential nucleoside hydrolase) and YeiL was inferred by showing that the yeiK and yeiL genes are divergently transcribed from overlapping promoters. A $10-15 \%$ deficiency in aerobic growth yield and an enhanced loss of viability under nitrogen starvation conditions were detected with a yeiL:: $k^{2} n^{R}$ mutant, suggesting that Yeil might function as a post-exponential-phase nitrogenstarvation regulator.

Keywords: CRP-FNR protein superfamily, iron-sulphur proteins, transcriptional regulation, nitrogen starvation, stationary phase

\section{INTRODUCTION}

The CRP-FNR family of transcription regulators contains at least 70 members that respond to a variety of metabolic and environmental signals to control a diverse range of physiological functions in an equally diverse range of bacteria (Spiro, 1994; Guest et al., 1996; Vollack et al., 1999). The family can be divided into three broad phylogenetically distinct groups designated CRP, NtcA and FNR, although there is considerable variation within the groups and also some overlap between the groups with respect to functional specifi-

Abbreviations: CRP, CAMP receptor protein; FNR, fumarate and nitrate reduction regulator; MALDI-TOF, matrix-associated laser desorption ionization-time of flight; MBP, maltose-binding protein. cities for signal recognition, DNA-binding, and RNA polymerase interaction (where known). The CRP group mainly contains transcription factors that regulate catabolite-sensitive genes in response to glucose starvation as signalled by cAMP (Busby \& Kolb, 1996). The NtcA group is more diverse because it includes regulators of cyanobacterial nitrogen and sulphur metabolism as well as others concerned with CO metabolism and oxygen-dependent nitrate reduction in Rhodospirillum and Bacillus species, respectively. The FNR group is currently the largest group. It contains three phylogenetically distinct subgroups designated FnrN/ AadR, FixK and DNR/FLP in addition to the FNR subgroup, which contains the archetypal FNR proteins that regulate oxygen-dependent gene expression via the anaerobic acquisition of oxygen-labile $[4 \mathrm{Fe}-4 \mathrm{~S}]$ clusters 


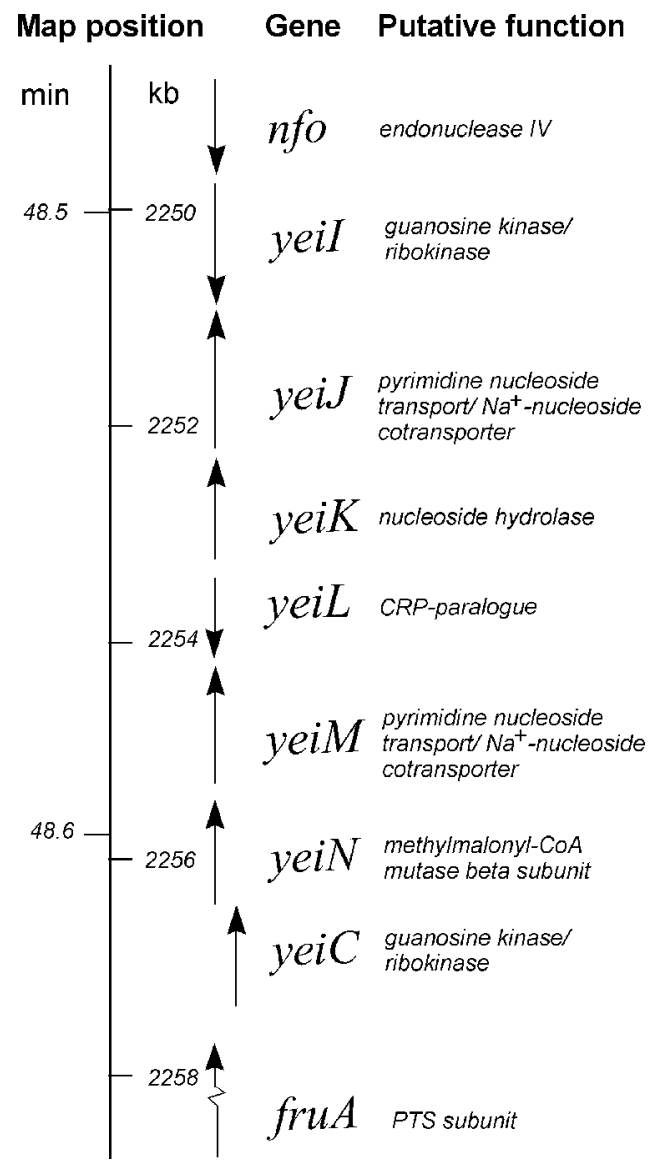

Fig. 1. Map of the $n f o-f r u A$ region of the $E$. coli chromosome. The positions and polarities of the genes and unidentified reading frames from Blattner et al. (1997) are indicated together with the functions or predicted functions based on BLAST similarity searches.

(Kiley \& Beinert, 1999). The FnrN/AadR subgroup represents a cluster of FNR proteins from nitrogenfixing and photosynthetic bacteria whereas the FixK proteins regulate rhizobial nitrogen fixation by virtue of their own oxygen-dependent biosynthesis (Spiro, 1994). Finally, the DNR/FLP subgroup contains FNR-like proteins that regulate either denitrification in denitrifying bacteria (DNR, NNR) or oxidative stress in lactic acid bacteria (FLP, FlpA, FlpB). The FLP of Lactobacillus case $i$ was the first Gram-positive member of the family and it was recently shown to respond to oxidative stress via the reversible formation of intrasubunit disulphide bonds (Gostick et al., 1997, 1998). In each case the protein subunits are predicted to resemble CRP monomers by containing a C-terminal DNAbinding domain with a helix-turn-helix motif for sitespecific DNA-recognition, a long $\alpha$-helix that forms a dimer interface, and an N-terminal sensory domain based on a series of $\beta$-strands (Schultz et al., 1991). The two structural domains also provide specific activating contacts with RNA polymerase (Busby \& Ebright, 1997; Li et al., 1998).
The complete genome of Escherichia coli (Blattner et al., 1997) was recently shown to encode a third member of the CRP-FNR family (YeiL) when searched with a sequence profile derived from a multiple alignment of five members of the family: CRP and FNR from E. coli; FLP from L. casei; and FlpA and FlpB from Lactococcus lactis (Gostick et al., 1999). The YeiL protein (SWISSPROT accession no. P33023) is the 219-residue product of the $657 \mathrm{bp}$ yeiL open reading frame (GenBank accession no. U00007). A BLAST analysis showed that YeiL is more closely related to members of the CRPFNR family (16-22\% identical, $42-45 \%$ similar) than to other known proteins. A phylogenetic tree derived from 38 members of the CRP-FNR family indicated that YeiL is a distant relative of the CRP group (Gostick et al., 1999).

The yeiL gene is located in the $n f o-f r u A$ region of the E. coli linkage map at $48.57 \mathrm{~min}$ (co-ordinates 2253.38 to $2254.03 \mathrm{~kb}$; Blattner et al., 1997), where it is flanked by a cluster of unidentified reading frames, URFs (Fig. 1). Putative functions have here been assigned to the products of these URFs by similarity searches. They include two potential guanosine kinases, YeiC (P30235) and YeiI (P33020), which are 38\% identical $(61 \%$ similar), and two potential pyrimidine nucleoside transport proteins, YeiJ (P33021) and YeiM (P33024), which are $88 \%$ identical $(95 \%$ similar). There is also a potential nucleoside hydrolase, YeiK (P33022), which is $40 \%$ identical (66\% similar) both to YbeK (P41409; an unlinked E. coli URF) and to the inosine-uridine nucleoside hydrolase of Crithidia fasciculata (Degano et al., 1996). At least 26 of the 27 residues surrounding the catalytic site of this trypanosomal purine salvage pathway enzyme are conserved in YeiK and YbeK. Thus it would appear that several genes involved in nucleoside metabolism are located in the $n f o-f r u A$ region of the E. coli chromosome together with a novel paralogue of CRP and FNR.

The aim of the present work was to characterize the YeiL protein and to define its function by investigating the physiological consequences of yeiL gene inactivation and the regulation of yeiL gene expression.

\section{METHODS}

Bacterial strains, plasmids and phages. These are listed in Table 1. An isogenic yeiL:: $k a n^{\mathrm{R}}$ derivative of W3110, JRG3827, was constructed as follows, using standard molecular biological procedures (Sambrook et al., 1989). The yeiL gene with $1028 \mathrm{bp}$ and $722 \mathrm{bp}$ flanking segments was PCRamplified from W3110 chromosomal DNA as a $2.41 \mathrm{~kb}$ fragment using two primers incorporating useful restriction sites (shown in bold): S449 (PstI SalI, 5'-TTTAACTGCAGTCGACTTGCCAAGAACGCCCAG-3') and S450 (SmaI BamHI， 5'-TTTAACCCGGGATCCTACCTGTTAGCGGCATC-3'). The entire fragment was cloned into pGEM-T Easy (Promega) to generate pGS1109 and after propagating in GM242 (dam) a 40 bp ClaI fragment in the yeiL coding region was replaced by inserting a $k a n^{\mathrm{R}}$ cassette $(1.2 \mathrm{~kb} S m a \mathrm{I}$ fragment) from pUC4-KIXX (Pharmacia) between end-filled ClaI sites to generate pGS1110. The location of the $\mathrm{kan}^{\mathrm{R}}$ 
Table 1. Bacterial strains, plasmids and phages

\begin{tabular}{|c|c|c|}
\hline $\begin{array}{l}\text { Strain, plasmid } \\
\text { or phage }\end{array}$ & Relevant genotype & Source or reference \\
\hline W3110 & $\operatorname{trpR} i c l^{\mathrm{c}}$ (prototroph) & Lab. collection \\
\hline JC7623 & recB21 recC22 sbcB15 sbcC201 & Kushner et al. (1971) \\
\hline JRG3826 & JC7623 yeiL:: kan $^{\mathrm{R}}$ & This work \\
\hline JRG3827 & W3110 yeiL:: kan $^{\mathrm{R}}$ & This work \\
\hline RK4353 & $\Delta(\operatorname{argF}-\operatorname{lac}) U 169$ & V. Stewart* \\
\hline RK5279 & $\Delta(\operatorname{argF}-l a c) U 169$ fnr-250 & V. Stewart* \\
\hline JRG3885 & $\operatorname{RK} 4353(\lambda \mathrm{G} 271)$ & This work \\
\hline JRG3886 & $\operatorname{RK} 5279(\lambda \mathrm{G} 271) f n r-250$ & This work \\
\hline JRG3887 & 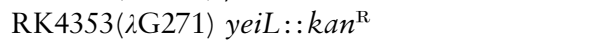 & This work \\
\hline JRG3888 & $\mathrm{RK} 5279(\lambda \mathrm{G} 271)$ fnr-250 yeiL:: $\mathrm{kan}^{\mathrm{R}}$ & This work \\
\hline JRG3889 & 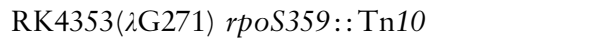 & This work \\
\hline JRG3890 & 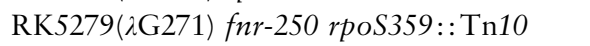 & This work \\
\hline JRG3891 & 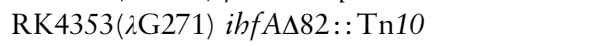 & This work \\
\hline JRG3892 & 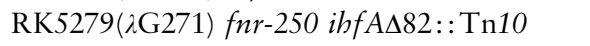 & This work \\
\hline JRG3893 & $\mathrm{RK} 4353(\lambda \mathrm{G} 271) \operatorname{lrp}:: \operatorname{Tn} 10$ & This work \\
\hline JRG3894 & $\mathrm{RK} 5279(\lambda \mathrm{G} 271) \operatorname{lrp}:: \operatorname{Tn} 10$ & This work \\
\hline CAG626 & lon lac $Z_{\mathrm{am}} \operatorname{trp}_{\mathrm{am}} p h o_{\mathrm{am}} \sup C_{\mathrm{ts}} m_{a l_{\mathrm{am}}} r p s L$ & NEB \\
\hline GM242 & dam-3 & Marinus \& Morris (1973) \\
\hline pGS1109 & $\begin{array}{l}\text { pGEM-T Easy with } 2.41 \mathrm{~kb} \text { yeiL containing } \\
\text { PCR fragment; } \mathrm{Ap}^{\mathrm{R}}\end{array}$ & This work \\
\hline pGS1110 & $\begin{array}{l}\text { pGS1109, with } 40 \text { bp ClaI deletion and } 1 \cdot 2 \\
\mathrm{~kb} \text { kan }^{\mathrm{R}} \text { insertion in the yeiL gene; } \mathrm{Ap}^{\mathrm{R}} \\
\mathrm{Km}^{\mathrm{R}}\end{array}$ & This work \\
\hline pGS1145 & $\begin{array}{l}\text { pGEM-T Easy with } 1046 \text { bp PCR-generated } \\
\text { yeiL promoter region; } \mathrm{Ap}^{\mathrm{R}}\end{array}$ & This work \\
\hline pGS1224 & $\begin{array}{l}\text { 1,042 bp EcoRI-BamHI yeiL promoter } \\
\text { fragment of pGS1145 cloned in pRS415; } \\
\mathrm{Ap}^{\mathrm{R}}\end{array}$ & This work \\
\hline pGS1225 & $\begin{array}{l}682 \text { bp PCR product containing the yeiL } \\
\text { coding region cloned in pGEM-T } \\
\text { Easy; } \mathrm{Ap}^{\mathrm{R}}\end{array}$ & This work \\
\hline pGS1226 & $\begin{array}{l}\text { yeiL coding region in } 673 \text { bp BamHI-SalI } \\
\text { fragment of pGS1225 cloned in pMal-c2; } \\
\text { Ap }^{\mathrm{R}}\end{array}$ & This work \\
\hline pGS1376 & $\begin{array}{l}\text { pSU19 with } 2.39 \mathrm{~kb} \text { yeiL containing } \\
\text { Pst } \mathrm{I}-\text { Bam HI fragment; } \mathrm{Cm}^{\mathrm{R}}\end{array}$ & This work \\
\hline$\lambda \mathrm{G} 271$ & $\begin{array}{l}\lambda \mathrm{RZ} 5 \text { derivative carrying the } y e i L-l a c Z \\
\text { fusion }\end{array}$ & This work \\
\hline
\end{tabular}

* Cornell University, Ithaca, NY, USA.

cassette was confirmed and its polarity shown to be the same as yeiL by sequence analysis before using pGS1110 to construct a yeiL::kan mutant of E. coli JC7623 ( $\mathrm{kecBC} s b c B C)$ according to Oden et al. (1990). The presence of the mutation was verified first by colony PCR with $\mathrm{Km}^{\mathrm{R}} \mathrm{Ap}^{\mathrm{S}}$ transformants using S449 and S450 as primers, which showed that the amplified product was $1.2 \mathrm{~kb}$ larger than with wild-type DNA, and second by Southern blot analysis of EcoRI- and PstIdigested DNA from a representative mutant (JRG3826) and the parental strain at high stringency $\left(0 \cdot 1 \%\right.$ SDS $\left.; 7{ }^{\circ} \mathrm{C}\right)$ with gel-purified and ${ }^{32} \mathrm{P}$-labelled $2.39 \mathrm{~kb}$ SalI-BamHI fragment of pGS1109 as a yeiL hybridization probe (Ready-To-Go DNA labelling kit and $\left[\alpha-{ }^{32} \mathrm{P}\right] \mathrm{dCTP}$; Amersham-Pharmacia). P1virmediated transduction was used to transfer the yeiL::kan ${ }^{\mathrm{R}}$ mutation to W3110 to generate JRG3827, and from the latter to RK4353 and RK5297 (Table 1). The rpoS, ihfA and lrp mutations of laboratory stocks were likewise transferred by P1 transduction in the construction of JRG3889-JRG3894 (Table 1). The $2.39 \mathrm{~kb}$ Pst I-BamHI fragment of pGS1109 containing the yeiL promoter and coding region was transferred to pSU19 (Martinez et al., 1988) to provide a low-copy (10 to 12) plasmid for complementation tests.

Media, growth conditions and viable counts. The rich media were Luria-Bertani (LB) and peptone broth (Green et al., 1997) supplemented with glucose $(0 \cdot 2 \%$ for aerobic growth and $1.0 \%$ anaerobic, unless stated otherwise) and antibiotics where required: kanamycin $\left(50 \mu \mathrm{g} \mathrm{ml}^{-1}\right)$; ampicillin $(150 \mu \mathrm{g}$ $\left.\mathrm{ml}^{-1}\right)$; tetracycline $\left(15 \mu \mathrm{g} \mathrm{ml}^{-1}\right)$; and chloramphenicol (normally $20 \mu \mathrm{g} \mathrm{ml}^{-1}$ but reduced to 10 and $5 \mu \mathrm{g} \mathrm{ml}^{-1}$ with lowcopy plasmid transformants in rich and minimal media, 
respectively). The citrate-containing minimal medium $\mathrm{E}$ (Vogel \& Bonner, 1956) was used routinely with sugars $(0.2 \%)$ and organic acids $(40 \mathrm{mM})$ as carbon sources, thiamin $(15 \mu \mathrm{M})$, and appropriate amino acid supplements. Cultures were grown from $1 \%$ stationary-phase inocula at $37^{\circ} \mathrm{C}$, either aerobically in conical flasks (with 0.1 vol. medium shaking at 200 r.p.m.) or anaerobically in sealed tubes $(10 \mathrm{ml}$ without shaking).

For carbon, phosphorus and nitrogen starvation, M9 medium was used with $0.02 \%$ glucose (normally $0.4 \%$ ), $0.25 \mathrm{mM}$ phosphate with $0.1 \mathrm{M}$ Tris/ $\mathrm{HCl}$ buffer $(\mathrm{pH} 7.6)$ and $0.2 \mathrm{mM}$ $\mathrm{NH}_{4} \mathrm{Cl}$, respectively (Davis et al., 1986), and the cultures $(600 \mathrm{ml})$ were maintained at $\mathrm{pH} 7 \cdot 4,90 \%$ air saturation (stirring speed, 200 r.p.m.) and $37^{\circ} \mathrm{C}$ in chemostat vessels for $7 \mathrm{~d}$. The inocula $(1 \%)$ were derived from single colonies from freshly streaked minimal plates, grown to stationary phase in M9 medium with $0.4 \%$ glucose. Serial dilutions of daily samples, plated in triplicate on pre-warmed LB agar and scored after $18 \mathrm{~h}$ at $37^{\circ} \mathrm{C}$, were used to determine viable counts (c.f.u. $\mathrm{ml}^{-1}$ ), which were then expressed as percentages relative to the $24 \mathrm{~h}$ values. All of the findings were reproducible in two or three independent experiments.

Protein purification. The yeiL coding region was PCRamplified from W3110 chromosomal DNA using forward primer S556 (5'-TTAAGGATCCCATATGAGTGAATCCGCGTTTAAGG-3') and reverse primer S559 (5'-TATGTCGACTTACGTCATCATCCCGGAGAATTTAT-3'), each incorporating flanking restriction sites. The $682 \mathrm{bp}$ product was cloned initially in pGEM-T Easy (Promega) and then between the BamHI-SalI sites of pMal-c2 (NEB) to place it downstream and 'in frame' with the maltose-binding protein (MBP) coding region and Factor $\mathrm{Xa}$ sensitive linker, to generate pGS1226. After confirmatory resequencing, pGS1226 transformants of E. coli CAG626 were used for overproduction and purification of the MBP-YeiL fusion protein. Soluble MBP-YeiL was purified from aerobic 2-litre cultures grown initially at $30{ }^{\circ} \mathrm{C}$ in LB plus $0 \cdot 2 \%$ glucose and ampicillin to $\mathrm{OD}_{600} 0 \cdot 2$, and then at $37^{\circ} \mathrm{C}$ for $1 \mathrm{~h}$ after adding IPTG $(0.3 \mathrm{mM})$. The bacteria harvested from one culture were washed and resuspended in $10 \mathrm{ml}$ buffer containing $20 \mathrm{mM}$ Tris/ $\mathrm{HCl}$ (pH 7.4), $200 \mathrm{mM} \mathrm{NaCl}$ and $1 \mathrm{mM} \mathrm{DTT,} \mathrm{for}$ ultrasonic disruption. The clarified cell-free extract was applied to an amylose column $(10 \mathrm{ml}$; NEB), washed with 20 vols of the same buffer, and eluted with buffer containing $10 \mathrm{mM}$ maltose.

Reconstitution of iron-sulphur clusters, and biochemical assays. The fusion protein was reconstituted using NifS from Azotobacter vinelandii according to Green et al. (1996). Typically, $1 \mathrm{ml}$ of the purified protein at a concentration of $1 \mathrm{mg} \mathrm{ml}^{-1}$ in a quartz cuvette was equilibrated in an anaerobic glove-box for 3-4 h on ice before adding DTT $(2.5 \mathrm{mM})$, Lcysteine $(1 \mathrm{mM}), \mathrm{Fe}^{2+}\left[40 \mathrm{~mol}\left(\mathrm{NH}_{4}\right)_{2} \mathrm{Fe}\left(\mathrm{SO}_{4}\right)_{2}\right.$ per mol MBPYeiL monomer] and NifS $(0.7 \mu \mathrm{M})$ to the stated final concentrations, and then incubated in the stoppered cuvette for up to $16 \mathrm{~h}$ at $4{ }^{\circ} \mathrm{C}$. Spectra were obtained with a Unicam UV-2 spectrophotometer (Pye-Unicam). The reconstituted protein was desalted anaerobically, using a Sephadex G25 column to remove excess reagent. Iron and sulphur contents were determined by the methods of Woodland \& Dalton (1984) and Beinert (1983), respectively. Reactive thiol groups and the disulphide contents of the native protein were assayed according to Thelander (1973) and Thannhauser et al. (1987), respectively.

Protein analysis, gel filtration and mass spectrometry. Protein was assayed by the Bio-Rad procedure with bovine serum albumin as standard, and the Laemmli method (Sambrook et al., 1989) was used for SDS-PAGE. Native molecular masses were determined by gel filtration with a Protein-Pak 300SW column $(7 \cdot 8 \times 300 \mathrm{~mm})$ equilibrated with $0 \cdot 2 \mathrm{M} \mathrm{NaH}{ }_{2} \mathrm{PO}_{4}$ (pH 6.7) containing $0.2 \mathrm{M} \mathrm{Na}_{2} \mathrm{SO}_{4}$ : DTT $(1 \mathrm{mM}$ ) was added to the buffer when reducing conditions were required. Thyroglobulin, catalase, lactate dehydrogenase, bovine serum albumin, ovalbumin, chymotrypsin, ribonuclease, aprotonin and myoglobin were the standards used for calibration. Nterminal amino acid sequences were determined by Edman degradation using an Applied Biosystems protein sequencer. Accurate molecular mass measurements were made by electrospray and MALDI-TOF mass spectrometries.

Construction of a yeiL-lacZ transcriptional fusion and $\beta$ galactosidase assay. A yeiL-lacZ transcriptional fusion was constructed by PCR-amplification of the yeiL promoter region (1017 bp of upstream non-coding region and $25 \mathrm{bp}$ of yeiL coding region) with two primers containing embedded EcoRI and BamHI restriction sites: S470 (5'-TTCCGGAATTCTTGCCAAGAACGCCCAG-3') and S471 (5'-TAGGCGGATCCAATCCTTAAACGCGGAT-3'). The product was cloned into pGEM-T Easy (Promega), generating pGS1145, from which the 1046 bp EcoRI-BamHI promoter fragment was transferred to pRS415 (Simons et al., 1987) to generate pGS1224. The yeiL-lacZ promoter fusion was then transferred to $\lambda$ RZ5 by homologous recombination to yield $\lambda \mathrm{G} 271$, and monolysogenic derivatives of various hosts were selected and screened with $\lambda b 80 d e l 9 c, \lambda c 190 c 17$ and $\lambda v i r . \beta$-Galactosidase specific activities were assayed according to Miller (1972) using at least two independent cultures.

RNA extraction and primer extension analysis. The hot acid phenol procedure (Aiba et al., 1981) with rapid cooling was used to extract total RNA from aerobic stationary-phase cultures grown in peptone broth plus $0.2 \%$ glucose. Primer extension analysis was performed with $100 \mu \mathrm{g}$ RNA, $10 \mathrm{pmol}$ primer and AMV reverse transcriptase (50 U; NEB) by a procedure that allowed continuous incorporation of $\left[\alpha^{32} \mathrm{P}\right] \mathrm{dCTP}$ (Cunningham et al., 1997). The primers were: S557 (5'-TCACTCATCAATTGCTGCTT-3') for yeiL; and both S499 (5'-TCGCCGCCATCATTATAG-3') and S558 (5'ATCCAGAATAATTTTTCTCTTTTCCA-3') for yeiK. The extension products were fractionated on $6 \%$ acrylamide $/ 7 \mathrm{M}$ urea gels alongside sequence ladders derived from pGS1109 and the corresponding primers (Cunningham et al., 1997).

\section{RESULTS}

\section{The yeiL gene encodes a paralogue of CRP and FNR}

The YeiL protein contains 219 amino acid residues, and has a total molecular mass of $25294 \mathrm{Da}$ and a predicted pI of $8 \cdot 23$. Sequence comparisons with representative members of each subgroup of the CRP-FNR family showed that YeiL is : $22 \%$ identical (42\% similar) to the FNR of E. coli; $19 \%$ identical ( $45 \%$ similar) to the FLP of L. casei; $19 \%$ identical ( $44 \%$ similar) to the FixK of Rhizobium meliloti; and $17 \%$ identical (45\% similar) to the CRP of E. coli.

A multiple sequence alignment of YeiL, CRP and FNR (Fig. 2) confirmed their close relationships and indicated that most of the secondary structural elements of CRP are retained by YeiL. The alignment shows that the glycine and proline residues flanking some of the $\beta$ strands of the $\beta$-roll in CRP are conserved in YeiL. The 


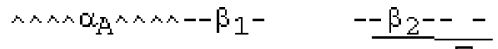$$
\text { CRF VLGKFOTDPTLENFLSHCHIHKYP-SK-5TLIHOFE } 34
$$$$
\text { YeiL MSEGAFKDCFLTDVGADTRLFHF - LAR-DYTVQEGO } 34
$$$$
\text { FNR MIPEKIIRRIQGGGCADHCOD CSISQLCIPFTLNEH ELDQLDNI-IERKKP IQKGQTLFKAGD } 63
$$

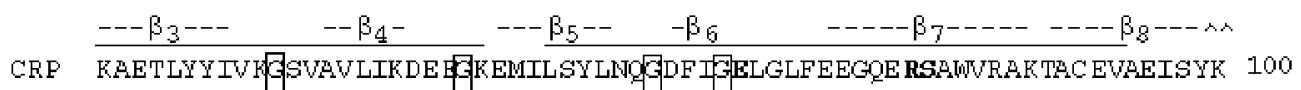

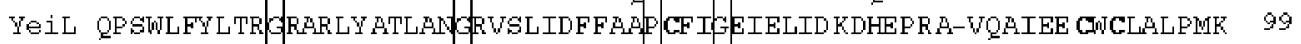

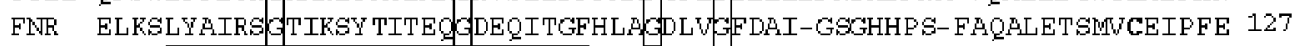

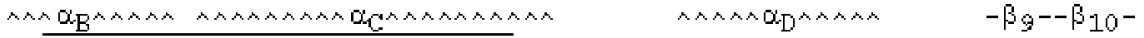

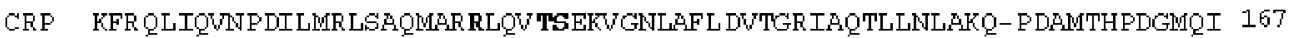$$
\text { YeiL HYRPLLWDTLFLRLCNTLSHKWYNIVSLT MOSFPLVTRLAAFIL----------LSOEGDLY } 155
$$$$
\text { FNR TLDDLGGKMPNLRQOMM LMSGEIKGDQDWILLLGKKNAEERLAAFIYNLGRRFAQRGFGPREFL } 193
$$

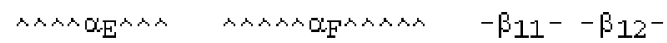$$
\text { CRP KITR QEIGRIVGCG RETWGRIL KMLEDQNLISAHGKTIVWGTR } 209
$$$$
\text { YeiL HEKHTQAAEYLGWGPHLLYLAOFIHDGLLIKGKKGYLIKNR KOLGGLALEMDF ENJKFGMWO } 219
$$$$
\text { FNR TMTRGDIGNY LGLTVET'I SRLLGRFOKSOMLAWKGKYITIENDDALAOLAGHTRNVA }
$$

\begin{abstract}
Fig. 2. Multiple alignment of the $E$. coli CRP, YeiL and FNR amino acid sequences generated by the GCG program PILEUP. The regions of greatest sequence conservation identified by DIAGON (Staden, 1982) are denoted by lines above the CRP sequence and below the FNR sequence. Secondary structural elements in CRP (Schultz et al., 1991) are indicated above the alignment, and conserved glycine and proline residues that flank $\beta$-strands are boxed. The residues involved in cAMPbinding by CRP and the cysteine residues in YeiL and FNR are shown in bold. The DNA-recognition motifs in the relevant $\alpha$-helices $\left(\alpha_{F}\right)$ of CRP and FNR are shown in bold and underlined.
\end{abstract}

regions of greatest sequence similarity $(P \leqslant 0 \cdot 001)$ identified by pairwise DIAGON comparisons (Staden, 1982) between YeiL and either CRP or FNR are also indicated in Fig. 2. These are different in each case but they represent major structural features such as the sensory domain $\left(\beta\right.$-roll) and dimer interface $\left(\alpha_{\mathrm{C}}\right)$ of CRP and the DNA-recognition helix $\left(\alpha_{\mathrm{F}}\right)$ of FNR. In addition, the presence of a characteristic helix-turn-helix structure $\left(\alpha_{\mathrm{E}}-\alpha_{\mathrm{F}}\right)$ was strongly predicted by the GCG program HELIX-TURN-HELIX. However, the motifs associated with the DNA-binding specificities of FNR (E--SR) and CRP (RE--G) in $\alpha_{\mathrm{F}}$ (Guest et al., 1996) are not conserved in YeiL, suggesting that YeiL recognizes different sites to those recognized by both FNR and CRP.

In terms of signal recognition, only one of the six residues involved in cAMP-binding in CRP is conserved in YeiL (Fig. 2), suggesting that cAMP is not a coeffector for YeiL. YeiL also lacks the cysteine-rich $\mathrm{N}$-terminal extension that provides three of the four ligands for the sensory iron-sulphur cluster of FNR. However, YeiL contains five cysteine residues: one is near the $\mathrm{N}$ terminus (C9) and four are centrally located (C68- $\mathrm{X}_{22}{ }^{-}$ $\left.\mathrm{C} 91-\mathrm{X}_{1}-\mathrm{C} 93-\mathrm{X}_{22}-\mathrm{C} 116\right)$. Of these, $\mathrm{C} 91$ and $\mathrm{C} 93$ are predicted to reside in the same $\beta$-strand $\left(\beta_{8}\right)$ as the fourth iron ligand (C122) of FNR (Fig. 2). It is also relevant to note that the two cysteine residues (C5 and C102) participating in reversible intra-subunit dithioldisulphide formation in FLP are likewise predicted to reside near the $\mathrm{N}$-terminus and in $\beta_{8}$, respectively (Gostick et al., 1998, 1999).

The cysteine residues in YeiL were modelled at the corresponding positions in the X-ray structure of the
cAMP-CRP-DNA complex (Schultz et al., 1991) as shown in Fig. 3(a). This hypothetical structure suggested that a disulphide bond could be formed between the cysteine residues (C116) at the dimer interfaces of two subunits. The measured distance between the $\beta$ carbon atoms $\left(\mathrm{C}_{\beta}\right)$ of $\mathrm{C} 116_{\mathrm{A}}$ and $\mathrm{C} 116_{\mathrm{B}}$ in the model was $4.76 \AA$, which is close to the values found in typical protein disulphides, 3.7 to $4.3 \AA$ ( $1 \AA=0 \cdot 1 \mathrm{~nm})$. The model also suggested that three of the cysteine residues (C68, C91 and C93) could potentially serve as ligands for the assembly of an iron-sulphur cluster in each monomer (Fig. 3a). The inter-molecular distances between their $\mathrm{C}_{\beta}$ s were measured as $10 \cdot 6 \AA$ (C68-C91), $5 \AA$ (C91-C93) and $10 \cdot 2 \AA$ (C93-C68). Then, by using the threedimensional-database search program AssAM (Artymiuk et al., 1994), it was found that this arrangement of three cysteine residues is most closely matched by that associated with the $[4 \mathrm{Fe}-4 \mathrm{~S}]$ cluster of porcine mitochondrial aconitase (Robbins \& Stout, 1989), where the corresponding inter-molecular distances are $8 \AA$ (C358C421), $4.76 \AA$ (C421-C424) and $8 \AA$ (C424-C358). The relevant cysteine residues of YeiL and aconitase are superimposed in Fig. 3(b) and it is predicted that such a [4Fe-4S] cluster could be accommodated by YeiL. The fourth iron ligand could be provided by one of the remaining cysteine residues (C9 and $\mathrm{C} 116$, from the same or an adjacent subunit), by a hydrogen-bonded water molecule (as found in aconitase), or by some other residue. From these structural predictions it is conceivable that the proposed transcription regulatory activity of YeiL might be modulated by a sensory iron-sulphur cluster (as in FNR), by reversible disulphide formation, or by a combination of both mechanisms. Intra-molecular disulphide bridges could 


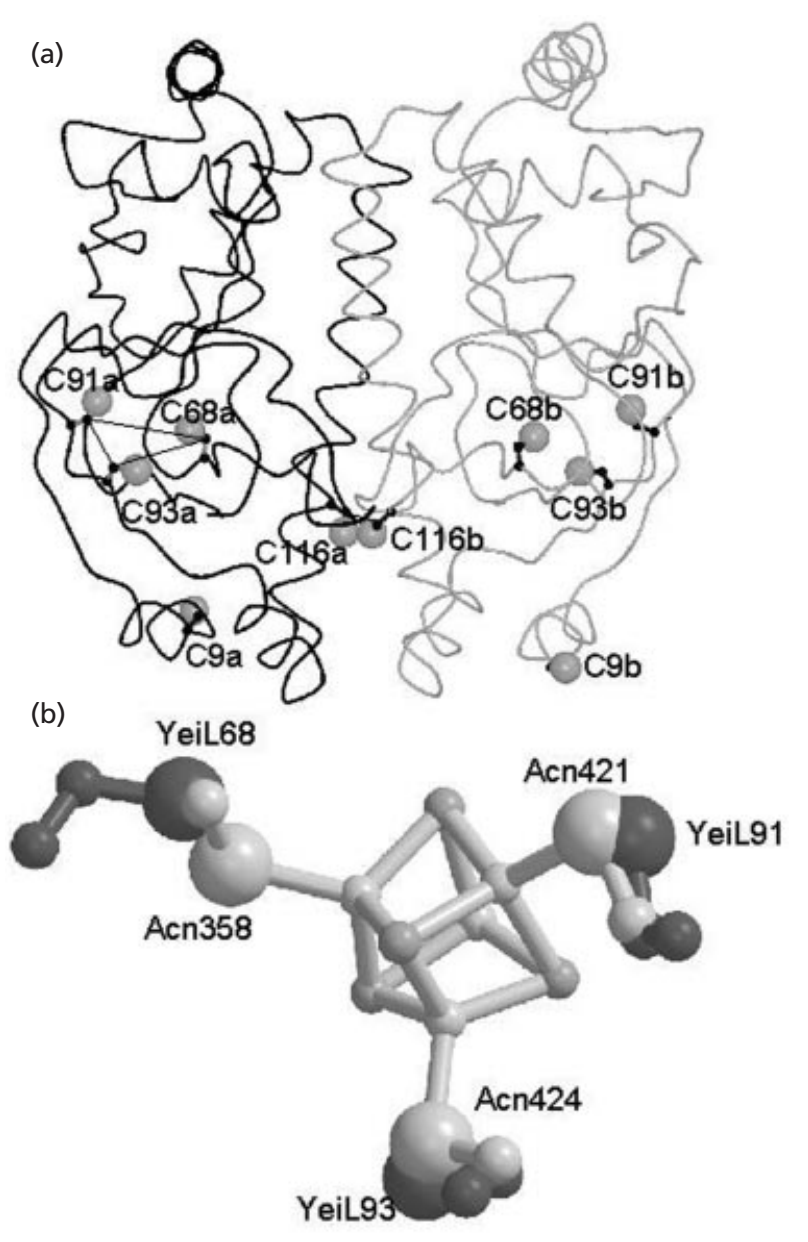

Fig. 3. Hypothetical model of a YeiL dimer and spatial organization of a potential iron-sulphur cluster. (a) model of a YeiL dimer based on the three-dimensional structure of the CAMP-CRP-DNA complex (Schultz et al., 1991), drawn with MOLSCRIPT (Kraulis, 1991). The cysteine residues are shown with space-filling sulphur atoms (light spheres) and distances were measured between the pairs of $C_{\beta}$ atoms connected by lines. (b) Spatial positioning of cysteine sulphur atoms co-ordinating the iron atoms of a hypothetical iron-sulphur cluster in YeiL (dark spheres) compared to a [4Fe-4S] cluster in mitochondrial aconitase (light spheres).

be formed between the cysteine residue near the $\mathrm{N}$ terminus and a centrally located cysteine residue (as in FLP) or between another pair(s) of cysteine residues. Alternatively, inter-molecular disulphide bonds could be formed between independent subunits at the dimer interface, e.g. between C116a and C116b (Fig. 3a), or at other sites.

\section{Overproduction and purification of YeiL}

The 657 bp yeiL coding region was PCR-amplified from chromosomal DNA and cloned into a variety of expression vectors in order to overproduce and purify the YeiL protein. Most of the strategies, including IPTG-induced expression of intact YeiL and several

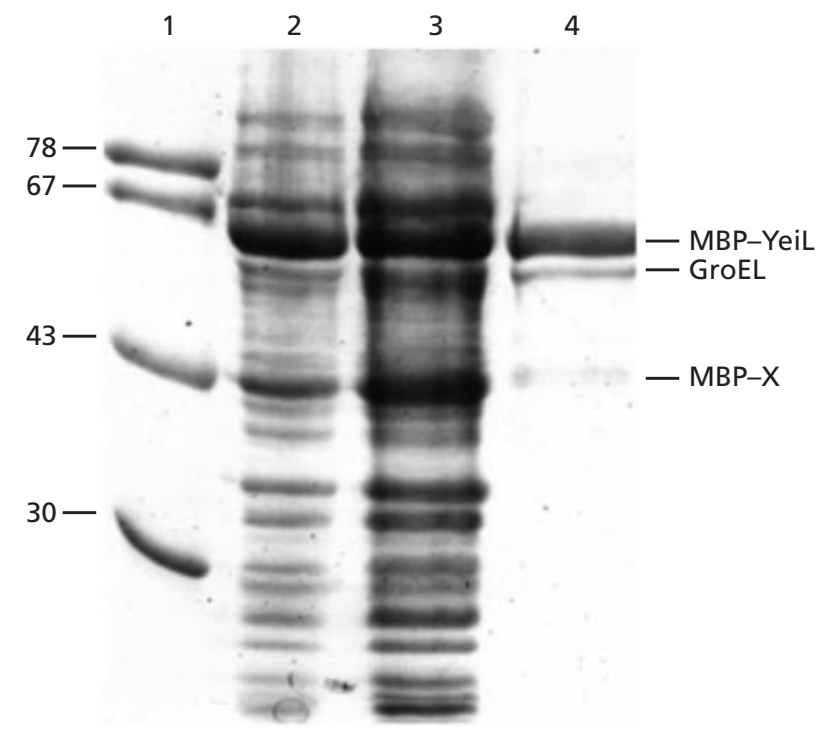

Fig. 4. Overproduction and purification of the MBP-YeiL fusion protein. Coomassie-blue-stained SDS-PAGE gels showing: lane 1 , protein standards; lane 2 , suspension of induced bacteria (10 $\mu \mathrm{g}$ protein); lane 3 , soluble cell-free extract $(15 \mu \mathrm{g}$ protein); lane 4, amylose-affinity-purified MBP-YeiL (5 $\mu \mathrm{g}$ protein). The positions of the fusion protein, GroEL, a degradation product (MBP-X), and the standards (ovotransferrin, $78 \mathrm{kDa}$; bovine serum albumin, $67 \mathrm{kDa}$; ovalbumin, $42.7 \mathrm{kDa}$; and carbonic anhydrase, $30 \mathrm{kDa}$ ), are indicated.

fusion proteins (GST-YeiL, $\mathrm{His}_{6}$-YeiL and YeiL-His ${ }_{6}$ ), were unsuccessful despite achieving high yields of amplified protein. This was largely because most of the amplified protein was insoluble even after low-temperature expression. Although the insoluble fraction could be solubilized by detergents and chaotropic ions (but not reducing agents), it invariably reprecipitated upon controlled removal of these agents, in the presence or absence of reductants. Furthermore, the small amount of soluble material in cell-free extracts was heavily contaminated by chaperone proteins. However, a soluble fusion protein was obtained by cloning the yeiL coding region downstream of the gene encoding a truncated maltose-binding protein (MBP) in pMal-c2 to generate pGS1226. The truncated MBP lacks a signal sequence; hence the MBP-YeiL fusion remained in the cytoplasm. In typical experiments, IPTG-induced cultures of CAG626(pGS1226) overproduced a protein having a subunit mass of $\sim 66000 \mathrm{Da}$ (predicted mass $68417 \mathrm{Da}$ including the linker); $90 \%$ of this protein remained in the soluble fraction, where it represented $\sim 8 \%$ of total soluble protein, as estimated by quantitative densitometry of Coomassie-stained gels (Fig. 4). It was purified to $\geqslant 85 \%$ homogeneity in a single step by amylose affinity chromatography (Fig. 4) in final yields of 4-7 mg MBP-YeiL fusion protein per litre of culture. $\mathrm{N}$-terminal sequence analysis confirmed that the $\sim 66000$ Da component is an MBP fusion, and it also showed that the major contaminants are GroEL (the $\sim 60000$ Da band) and MBP-X (the 43000 Da band), 
(a)
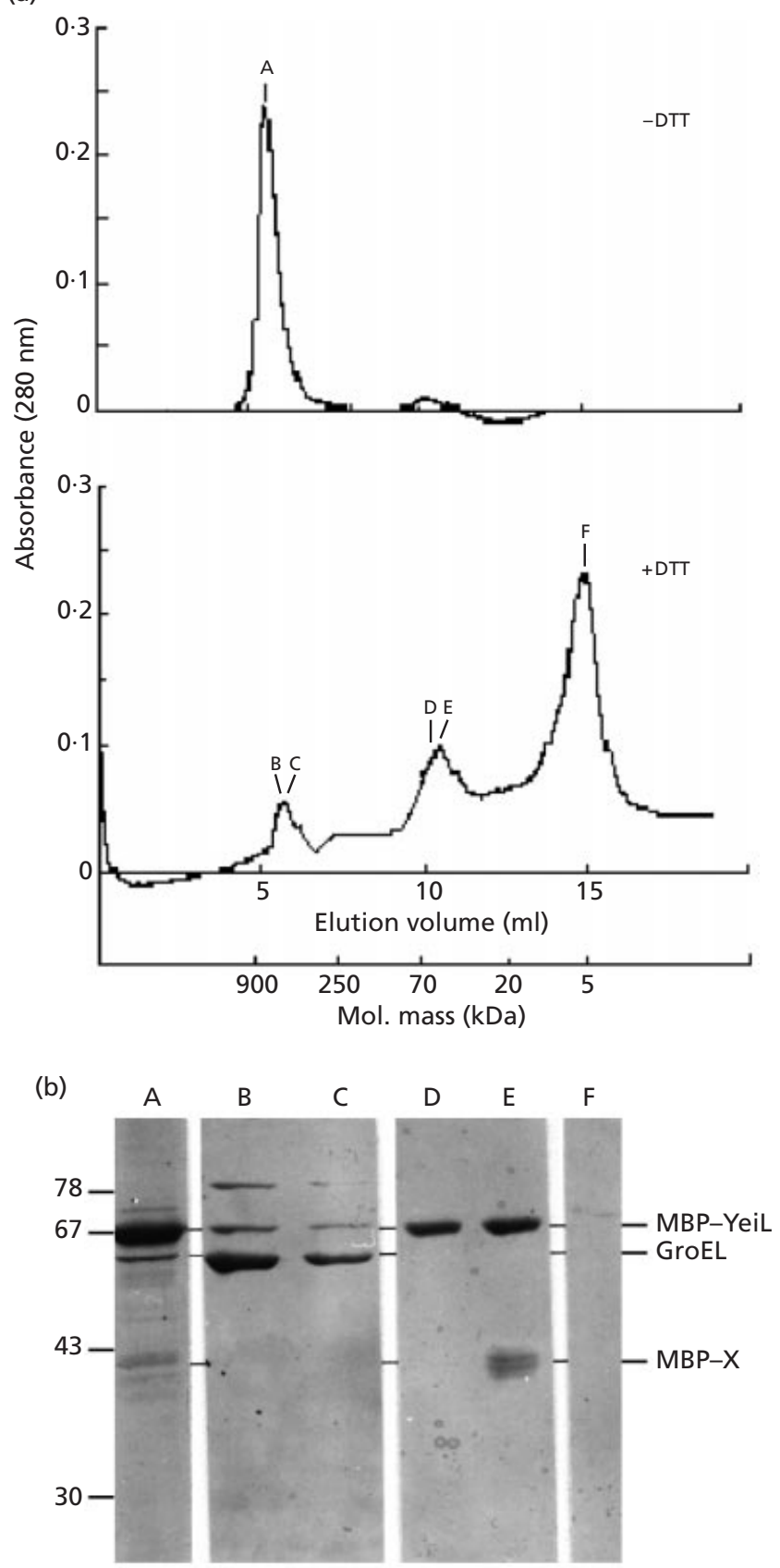

Fig. 5. Gel filtration analysis of MBP-YeiL. (a) Elution profiles of purified MBP-YeiL $(100 \mu \mathrm{g})$ obtained with no DTT in the sample or elution buffer (upper panel) and with $4 \mathrm{mM}$ DTT in the sample and $1 \mathrm{mM}$ DTT in the elution buffer (lower panel). The molecular mass scale was derived from the elution volumes of standard proteins. (b) Silver-stained SDS-PAGE gel of the fractions marked by letters in (a); the absorbance marked $F$ was due to DTT. The positions of known components and standards are indicated.

presumed to be a degradation product of MBP-YeiL because the host strain lacks intact MBP, predicted mass $42000 \mathrm{Da}$ (Fig. 4). Factor Xa-mediated cleavage of YeiL from the fusion was very poor, so MBP-YeiL was used in all subsequent studies. It was argued that the MBP moiety would not interfere with the biochemical characterization because it lacks cysteine and because it has been used successfully in characterizing a synthetic iron-sulphur protein (Benson et al., 1998). As isolated the MBP-YeiL protein was extremely labile and prone to precipitation but could be stored for up to $10 \mathrm{~d}$ at $4{ }^{\circ} \mathrm{C}$ in the buffer containing $1 \mathrm{mM}$ DTT.

\section{Biochemical characterization of the MBP-YeiL fusion protein}

Gel filtration analysis indicated that freshly prepared native fusion protein exists as a high-molecular-mass oligomer or aggregate of $>300000 \mathrm{Da}$ (Fig. 5a). SDSPAGE and N-terminal sequence analysis showed that the purified protein contained GroEL and some lowermolecular-mass components that are probably degradation products of the unstable MBP-YeiL protein (Fig. $5 \mathrm{~b}$, lane A). However, when analysed in the presence of DTT $(4 \mathrm{mM}$ in the sample and $1 \mathrm{mM}$ in the elution buffer) only a small fraction of the fusion protein $(\sim 10 \%)$ was associated with GroEL and the rest eluted as a monomer which was still very prone to degradation (Fig. 5a and b, lanes $\mathrm{B}$ and $\mathrm{C}$ versus $\mathrm{D}$ and $\mathrm{E}$ ) : no dimeric MBP-YeiL was detected. Mass spectrometry served mainly to illustrate the instability of the fusion protein because much of the protein appeared to be degraded to products of 44646 and $57322 \mathrm{Da}$ and the corresponding homo- and hetero-dimers (89300, 102000 and $114600 \mathrm{Da})$. Nevertheless, molecules of $68700 \mathrm{Da}$ (MALDI-TOF) and $68478 \mathrm{Da}$ (electrospray), representing monomeric MBP-YeiL (predicted $68417 \mathrm{Da}$ ), were detected. The extra mass could be due to protein modification or remnants of degraded iron-sulphur clusters, as observed previously with FNR (Green et al., 1993). Assuming that the MBP moiety is stable, the sizes of the major degradation products indicated that they retain either one cysteine residue (C9) or all five cysteine residues (C9, C68, C91, C93 and C116). This suggests that C9 and C116 may be located on the surface of the YeiL moiety, where intra- and inter-molecular disulphide bridges lead to the formation of stable monomeric and dimeric degradation products. The presence of the latter further suggests that C9 and C116 might participate in the reversible formation of disulphide-linked YieL dimers. It was also inferred that the oligomeric form of MBP-YeiL detected by gel filtration (Fig. 5a) might be a non-covalent aggregate of either monomers or disulphide-bonded dimers (because it is disaggregated by DTT).

Purified MBP-YeiL contained substoichiometric amounts of iron and acid-labile sulphide (Table 2). This suggested that at least a fraction of the protein retained an iron-sulphur cluster or degradation products therefrom, as is frequently observed with iron-sulphur proteins. After anaerobic reconstitution of potential iron-sulphur clusters, the iron content increased to approximately four per monomer but less sulphide was incorporated (Table 2). The procedure for detecting 
Table 2. Biochemical analysis of MBP-YeiL

The iron and acid-labile sulphide contents were assayed before and after anaerobic NifS-mediated reconstitution and desalting; the net contents of free thiol groups and disulphide bonds were determined with samples of the native protein dialysed versus DTT-free buffer. The quoted values were derived from at least two independent preparations and have been adjusted to allow for the $15 \%$ contamination by GroEL.

\begin{tabular}{|lccccc|}
\hline \multirow{2}{*}{ MBP-YeiL } & \multicolumn{4}{c|}{ Chemical composition (mol per mol of MBP-YeiL monomer) } \\
\cline { 2 - 6 } & Fe & Acid-labile S & Fe/S ratio & Free SH & Disulphide \\
\hline Native (as prepared) & $0 \cdot 28-0 \cdot 36$ & $0 \cdot 12-0 \cdot 25$ & $1 \cdot 7-2 \cdot 2$ & $2 \cdot 9-3 \cdot 4$ & $0 \cdot 96-0 \cdot 98$ \\
Reconstituted & $3 \cdot 80-4 \cdot 40$ & $2 \cdot 59-3 \cdot 29$ & $1 \cdot 3-1 \cdot 5$ & ND & ND \\
\hline
\end{tabular}

ND, Not determined.

acid-labile sulphide (Beinert, 1983) requires disruption of the protein without precipitation, which is more difficult if the $\mathrm{Fe}-\mathrm{S}$ cluster is stable. The results would therefore be consistent with MBP-YeiL acquiring one relatively stable $[4 \mathrm{Fe}-4 \mathrm{~S}]$ cluster per monomer. Anaerobic NifS-catalysed reconstitution for $16 \mathrm{~h}$ in a sealed cuvette was accompanied by the acquisition of a straw-brown appearance and an increase in absorbance at $420 \mathrm{~nm}$, giving a spectrum that is typical of ironsulphur proteins. The molar absorption coefficient $\left(\varepsilon_{420}\right)$ of reconstituted MBP-YeiL was $19750 \mathrm{M}^{-1}$ $\mathrm{cm}^{-1}$ (allowing for the $85 \%$ purity of the samples analysed). This is somewhat higher than the value of $17200 \mathrm{M}^{-1} \mathrm{~cm}^{-1}$ for the model compound $\left[\mathrm{Fe}_{4} \mathrm{~S}_{4}(\mathrm{~S}-\mathrm{Et})_{4}\right]^{2-}$, but it is much higher than the $\varepsilon_{420}$ values of typical $[2 \mathrm{Fe}-2 \mathrm{~S}]^{2+}$ clusters, 9000$11000 \mathrm{M}^{-1} \mathrm{~cm}^{-1}$ (Holm \& Ibers, 1977).

The stability of the putative iron-sulphur cluster was investigated by exposing anaerobically reconstituted and desalted MBP-YeiL to air in a spectrophotometer cuvette while recording the UV-visible spectrum. The absorbance at $420 \mathrm{~nm}$ declined slowly by $10 \%$ over a period of $100 \mathrm{~min}$ and there was a corresponding increase at $330 \mathrm{~nm}$, after which the solution became turbid due to protein precipitation. Similar experiments with reconstituted FNR have shown that protein precipitation starts after $10 \mathrm{~min}$ exposure to air as a consequence of cluster degradation (Lazazzera et al., 1996). The increase in absorbance at $330 \mathrm{~nm}$ is frequently seen during the degradation (and acquisition) of the iron-sulphur clusters of FNR and related proteins, e.g. the FNR of Azotobacter vinelandii (Wu et al., 2000), but the reason is not known. Gel filtration analysis after reconstitution showed that $40 \%$ of the protein was released from the oligomeric form but it was rapidly degraded and again no dimers were detected.

As isolated, MBP-YeiL contained approximately three free thiol groups and one disulphide bond per monomer (Table 2). This is consistent with its being a multimeric aggregate linked by one inter-molecular disulphide bond per monomer. However, because three or four thiols might be used for assembling the iron-sulphur cluster, and because disulphide-bond formation could occur between thiols within and between monomers (including iron-liganding thiols after cluster disassembly), it is impossible to deduce the precise disposition of the five cysteine residues in YeiL. Nevertheless, YeiL clearly has the potential to assemble an iron-sulphur cluster and to form intra- and inter-molecular disulphide bonds, as predicted. By analogy with FNR and FLP the DNAbinding form of YeiL might be dimeric and its activity might likewise be modulated by a sensory iron-sulphur cluster, by reversible dithiol-disulphide formation, or by both mechanisms.

\section{Construction and phenotypic characterization of a yeil mutant}

The yeiL gene was disrupted by replacing a segment of the coding region by a $k a n^{\mathrm{R}}$ cassette (in vitro), then transferred to the E. coli chromosome (Oden et al., 1990), and ultimately to W3110 to generate JRG3827 $\left(y e i L:: \operatorname{kan}^{\mathrm{R}}\right)$. The growth patterns of the yeiL mutant (JRG3827) and its isogenic parent (W3110) were compared under aerobic, microaerobic and anaerobic $( \pm$ nitrate) conditions at $37^{\circ} \mathrm{C}$ in LB broth $( \pm$ glucose) and in minimal medium $\mathrm{E}$ containing different carbon sources. This showed that the growth yields $\left(\mathrm{OD}_{600}\right)$ achieved by the parental strain were consistently $10-15 \%$ higher than those of the mutant during aerobic growth in rich media and minimal media containing glucose, maltose or succinate. No differences in growth rates or other features of the growth cycle were observed between the mutant and parental strains. No complementation of the growth defect was observed with pGS1109 because this high-copy $y e i L^{+}$plasmid adversely affected the growth of both mutant and wild-type transformants, particularly in minimal media. In contrast, the growth yields $\left(\mathrm{OD}_{600}\right.$ after fourfold dilution) observed in $\mathrm{LB}$ medium for mutant and wild-type transformants containing a low-copy plasmid (pGS1376) increased by $10-14 \%$ and $25-30 \%$ (respectively) relative to the untransformed host strains. However, the deleterious effects again became apparent in minimal media, where complementation varied with substrate from very weak 

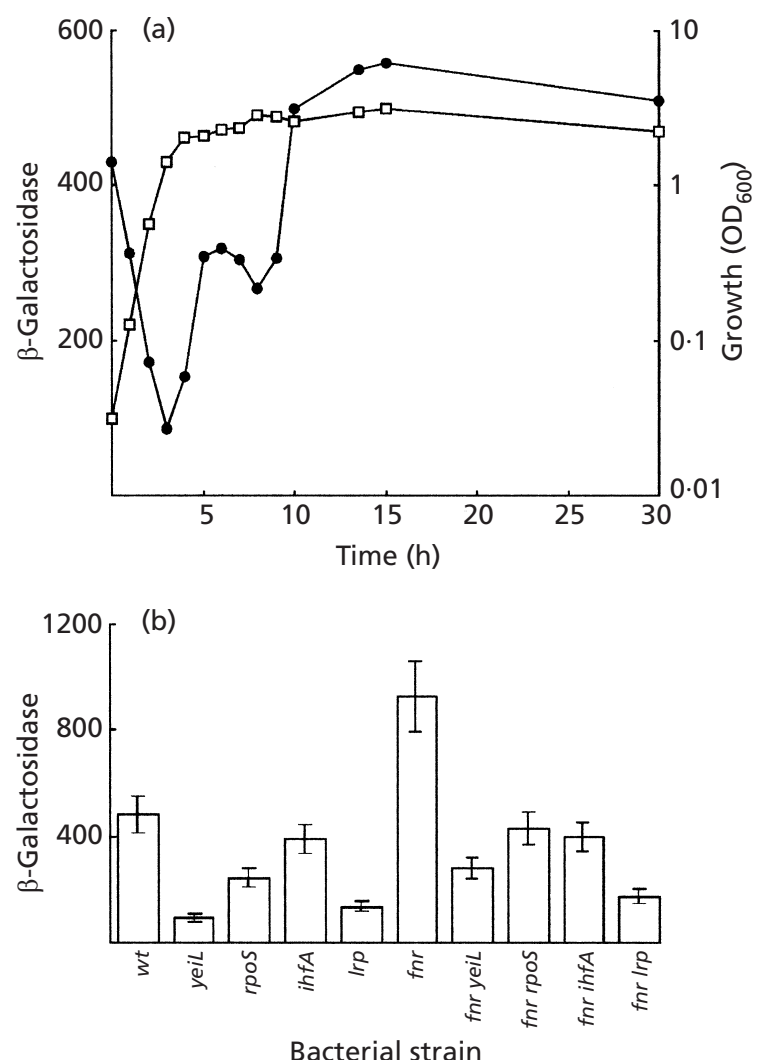

Fig. 6. Growth phase and factor-dependence of yeiL-lacZ expression. Cultures of $\lambda$ yeiL-lacZ ( $\lambda \mathrm{G} 271)$ monolysogens were grown at $37{ }^{\circ} \mathrm{C}$ from $1 \%$ stationary-phase inocula in peptone broth ( $50 \mathrm{ml}$, supplemented with $0.2 \%$ glucose) by shaking aerobically at 200 r.p.m. for $16 \mathrm{~h}$ (unless specified times are indicated). (a) Expression of the yeiL-lacZ transcriptional fusion during the growth cycle of JRG3885 (wild-type): $\square$, growth $\left(\mathrm{OD}_{600}\right)$;,$\beta$-galactosidase specific activity (Miller units). (b) Effects of regulator mutations on stationary-phase yeiL-lacZ expression (Miller units): mean values for four independent cultures are shown with standard deviations. The monolysogens and mean $\mathrm{OD}_{600}$ values of $16 \mathrm{~h}$ cultures were: wild-type (JRG3885, 2.86); yeiL (JRG3887, 2.2); rpoS (JRG3889, 2.5); ihfA (JRG3891, 2.4); Irp (JRG3893, 2.1); fnr (JRG3886, 2.78); fnr yeiL (JRG3888, 2.4); fnr rpoS (JRG3890, 2.6); fnr ihfA (JRG3892, 2.2); fnr Irp (JRG3894, 1.6).

(succinate) to insignificant (glucose) and detrimental (maltose).

\section{Studies with a yeiL-lacZ transcriptional fusion}

Insights into the temporal expression and regulation of the yeiL gene were sought by constructing monolysogens containing $\lambda \mathrm{G} 271$ prophages in which the yeiL promoter region is fused to a lac $Z$ reporter (see Methods). During aerobic growth in rich media yeiL expression increased $6 \cdot 5$-fold in stationary phase relative to late exponential phase (Fig. 6a) and the degree of induction relative to early exponential phase may have been even greater if exponential phase inocula had been used. The reason for the reproducible two-stage increase is not known. Similar high levels of expression were observed in late- stationary-phase cultures relative to exponential-phase cultures grown in glucose $(0.2 \%)$, glycerol $(40 \mathrm{mM})$ and succinate $(40 \mathrm{mM})$ minimal media (data not shown). However, the growth-phase-dependent response was not observed under anaerobic fermentative conditions, where the stationary-phase activities of the wild-type monlysogen (JRG3885) were about fourfold lower than those of the comparable aerobic cultures shown in Fig. 6(a) (data not shown).

Studies with monolysogens lacking YeiL or various transcription factors indicated that in the stationary phase aerobic yeiL expression is positively autoregulated by YeiL, and significantly dependent on RpoS $\left(\sigma^{\mathrm{S}}\right)$ and Lrp but not IHF (Fig. 6b). In contrast, there was a $\sim 1.9$ fold increase in stationary-phase yeiL expression in the fnr mutant (JRG3886) under both aerobic conditions (Fig. 6) and anaerobic fermentative conditions (data not shown), suggesting that yeiL transcription is directly or indirectly repressed by FNR. The fourfold decrease in stationary-phase yeiL expression observed under anaerobic conditions with the parental strain (JRG3885) was also observed with the fnr mutant (JRG3886), which suggests that YeiL may function primarily during the aerobic stationary phase. The requirements for YeiL, RpoS and Lrp for optimal yeiL expression were retained in the absence of FNR (Fig. 6b). Expression of the yeiL-lacZ fusion also became partly dependent on IHF in the $f n r$ background, suggesting that FNR and IHF may exert opposing negative and positive effects at overlapping binding sites in the yeiL promoter region.

\section{Identification of transcription start sites for the yeil and yeiK genes}

Primer extension analysis with RNA from cultures of two $f n r$ mutants, RK5279(pGS1109) and RK5279( $\lambda$ G271) (also designated JRG3886), chosen for their enhanced yeiL expression and sampled at different times in early stationary phase $(6-10 \mathrm{~h})$, revealed a single extension product, which was most abundant in the $8 \mathrm{~h}$ sample (Fig. 7a). This corresponded to a potential yeiL transcription start site located 65 bp upstream of the translation initiator codon and 7 bp downstream of a potential $\sigma^{70}$ or $\sigma^{\mathrm{s}}$ promoter containing plausible -35 (TTGAAT) and -10 (TATGCT) hexamers (Fig. 7b). The -35 hexamer is overlapped by a potential FNR site, which closely matches the FNR-site consensus (TTGAT- $\mathrm{N}_{4}$-ATCAA) and its location is consistent with the observed FNR-mediated repression of yeiL (Fig. 7c). There is a potential Lrp site (YAGHAWATTWTDCTR; $\mathrm{Y}=\mathrm{T}$ or $\mathrm{C} ; \mathrm{H}=\mathrm{A}, \mathrm{C}$ or $\mathrm{T} ; \mathrm{W}=\mathrm{A}$ or $\mathrm{T} ; \mathrm{D}=\mathrm{G}, \mathrm{A}$ or $\mathrm{T} ; \mathrm{R}=\mathrm{A}$ or $\mathrm{G}$; Cui et al., 1995) centred at -120 bp just inside the yeiK coding region, and there are two sequences matching the IHFsite consensus (WATCAANNNNTTR; Freundlich et al., 1992), which are consistent with the observed effects of Lrp and IHF on yeiL gene expression (Fig. 7c). There are two overlapping regions of partial dyad symmetry centred at -62 (TTTTCTacagcaaAGAAAA) and -64.5 (TTaTtTTTtCTacAGcAAAgAaAA), one of 

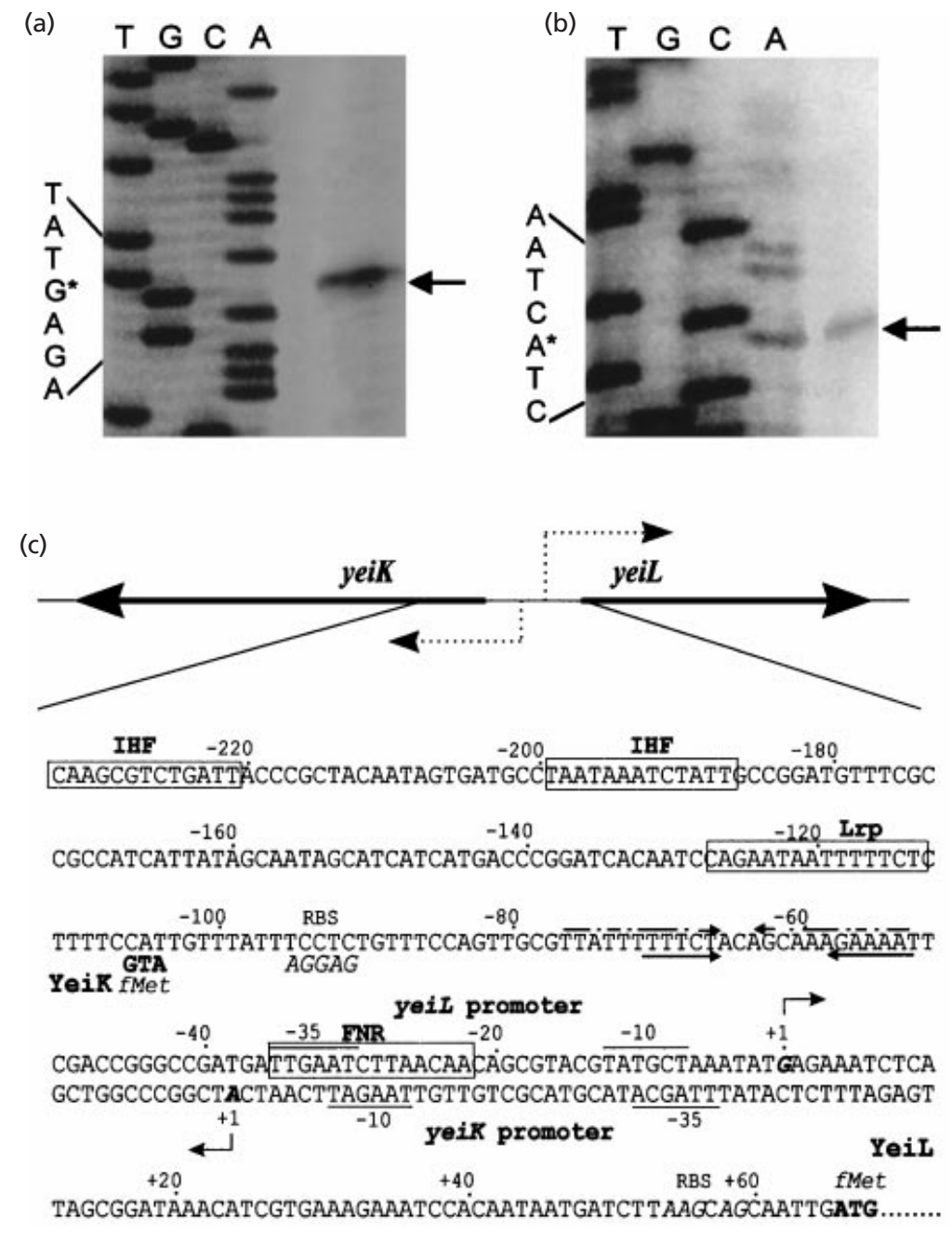

\begin{abstract}
Fig. 7. Primer extension mapping of potential yeiL and yeiK transcriptional start sites with RNA from cultures of RK5279(pGS1109) (fnr yeiL ${ }^{+}$). (a) Extension product of yeil transcript in RNA from an $8 \mathrm{~h}$ culture, aligned with a sequence ladder generated from pGS1109 and the same primer, S557. (b) Extension product of yeiK transcript in RNA from a $6 \mathrm{~h}$ culture and a sequence ladder generated from pGS1109 with the same primer, S558. (c) Nucleotide sequence of the yeiL and yeiK promoter region showing the presumed transcription start sites $(+1, \rightarrow)$, putative -35 and -10 hexamers (underlined or overlined); potential binding sites for FNR, Lrp and IHF (boxed); regions of partial dyad symmetry (converging arrows); ribosome-binding sites (RBS, consensus bases italicized), and translation initiators (fMet).
\end{abstract}

which could conceivably represent a YeiL-binding site associated with its positive autoregulatory effect on yeiL gene expression.

The transcription start site of the adjacent and divergent yeiK gene (Fig. 1) was identified by primer extension using the RNA samples from RK5279(pGS1109) and two different primers. Again, only one extension product was detected (Fig. 7b) and this corresponded to a potential yeiK start site located $66 \mathrm{bp}$ upstream of the YeiK initiator codon (Fig. 7c). There is a potential -10 hexamer with an extended -10 motif (TGnTAAGAT) located $7 \mathrm{bp}$ upstream of the start site. The most plausible -35 hexamer (TTAGCA) is located only $15 \mathrm{bp}$ upstream of the -10 hexamer, which is rather close for a typical $\sigma^{70}$ promoter, but the poor -35 site may be compensated by the extended -10 sequence. Thus it appears that yeiL and yeiK, the putative nucleoside hydrolase gene, are divergently transcribed from promoters in the same small segment of DNA. Transcription from one promoter may thus affect expression from the other. This is consistent with the primer extension experiments, which indicated that $y e i K$ transcripts are most abundant in $6 \mathrm{~h}$ RNA samples, where the yeiL transcripts are far less abundant.

\section{Starvation response of the yeiL mutant}

A role for YeiL in starvation survival was sought because the yeiL gene was more highly expressed in the postexponential phase. The viabilities of the yeiL::kan ${ }^{\mathrm{R}}$ mutant (JRG3827) and parent (W3110) were accordingly compared in M9 minimal medium under nonlimiting and under carbon-, phosphorus- and nitrogenlimiting conditions. Under carbon- and phosphatelimiting conditions the viabilities of both strains declined in parallel over $7 \mathrm{~d}$ (data not shown). However, when medium containing $0.2 \mathrm{mM} \mathrm{NH}_{4} \mathrm{Cl}(1 \%$ of the normal concentration) was inoculated with bacteria that had been pre-grown for $16 \mathrm{~h}$ in nitrogen-sufficient medium, modest but significant and reproducible differences in viability were observed (Fig. 8). After starting at comparable values, mutant viability fell to $10 \%$ during the second day compared to $75 \%$ for the parental strain. After $3 \mathrm{~d}$, mutant viability stabilized between $2 \%$ and $1 \%$ while parental viability continued to fall from $21 \%$ to $2 \%$ (Fig. 8). In comparable studies with a JRG3827 transformant containing the low-copy yeiL ${ }^{+}$plasmid (pGS1376), viability was partially restored from $10 \%$ to $63 \%$ (day 2 ) and $2 \%$ to $12 \%$ (day 3). It was therefore concluded that YeiL performs a direct or indirect role in 


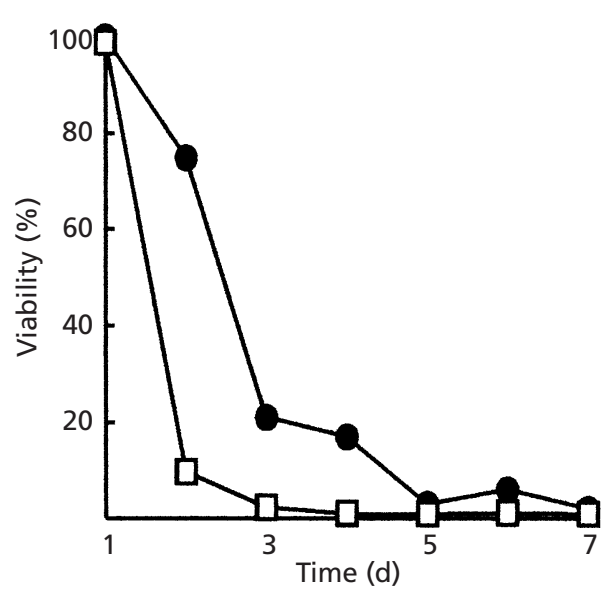

Fig. 8. Effects of yeil mutation on the nitrogen-starvation response. The viabilities (\% survival) of W3110 (O) and the yeiL:: $\operatorname{kan}^{\mathrm{R}}$ mutant JRG3827 ( $\square$ ) grown in N-deficient M9 medium are based on daily viable counts (c.f.u. $\mathrm{ml}^{-1}$, determined in triplicate) expressed as percentages of the comparable day 1 values. The data shown are typical of three independent experiments.

maintaining mid-term, but not long-term, stationaryphase viability under $\mathrm{N}$-starvation.

\section{DISCUSSION}

The yeiL gene of E. coli was predicted to encode a new and distinct member of the CRP-FNR family of transcriptional regulators that might have an ironsulphur centre and a reversible intra- or inter-molecular disulphide bond. Analysis of the purified MBP-YeiL fusion protein indicated that it is most probably a protein aggregate containing one inter-molecular disulphide bond (C9-C116 from different subunits) and three free thiols (C68, C91 and C93) per monomer (Fig. $3 a)$. Under reducing conditions this would permit the observed assembly of a [4Fe-4S] cluster liganded by the three free thiols and one other thiol (possibly C9), and the potential release of monomers. The monomers could in turn engage either in reversible inter-molecular disulphide formation between the C116 thiols to generate covalently linked dimers, or in intra-molecular disulphide formation (depending on the state of the iron-sulphur cluster) to generate non-covalent dimers. Compared to FNR (Green et al., 1996; Khoroshilova et al., 1997) the iron-sulphur cluster acquired by MBPYeiL had a much greater aerobic stability but the protein was itself less stable. This suggests that YeiL is not an oxygen-responsive regulator. Nevertheless, if the acquisition of the iron-sulphur is not simply fortuitous or for purely structural purposes, cluster assembly and the potential for reversible disulphide and dimer formation could provide functional switches for DNA-binding and transcription regulation analogous to those operating in FNR and FLP. Further elucidation of the molecular structure of YeiL and the regulatory switch was precluded by the insolubility and instability of the protein.
The problems experienced in amplifying YeiL as a soluble protein or fusion protein, the inherent instability of isolated MBP-YeiL, and the presence of GroEL as the main contaminant, may be functionally significant. They might indicate that considerable chaperone activity is needed to promote correct assembly of YeiL when overproduced. On the other hand they could mean that YeiL resembles the heat-shock sigma factor $\left(\sigma^{32}\right)$ in being associated with chaperones (DnaJ, DnaK, GrpE) which promote instability in unstressed bacteria, or in becoming resistant to proteolysis and hence functional when dissociated from chaperones in a stressed host (Gamer et al., 1996; Straus et al., 1990). $\sigma^{32}$ is also responsible for the induction of heat-shock proteins including GroEL under starvation conditions (VanBogelen \& Neidhardt, 1990), so the association of MBP-YeiL with GroEL may serve as a post-translational mechanism for controlling the concentration of functional YeiL during starvation. Alternatively, YeiL might resemble the temperature-sensing TlpA protein of Salmonella typhimurium, which is a DNA-binding regulator that can shift between unfolded monomeric and folded oligomeric states in response to changes in temperature by a process that involves inter-molecular disulphide formation (Hurme et al., 1997). However, the occurrence of the oligomeric form of TlpA at normal physiological concentrations is uncertain and the same might apply to the multimeric form of YeiL.

Clues about the role of YeiL came from studying the consequences of inactivating the yeiL gene and the use of a yeiL-lacZ reporter fusion to investigate yeiL gene expression under different physiological conditions and in different hosts. Studies with the yeiL:: $k_{a n}{ }^{\mathrm{R}}$ mutant (JRG3287) revealed a small but significant and reproducible deficiency in aerobic growth yield in several media and a remarkable enhancement of growth yield in rich medium by low-copy (but not high-copy) yeiL ${ }^{+}$ plasmids, especially in the wild-type host. Although the apparent increase in growth efficiency was not observed under all growth conditions it deserves further investigation as a mechanism for enhancing biotechnological productivity. The mutant also exhibited a specific deficiency in nitrogen-starvation survival, which was partially complemented by supplying yeiL $\mathrm{L}^{+}$in trans. It is not clear how the two features of the mutant phenotype are related. A role in the aerobic stationary phase was inferred from the very significant post-exponential increase in yeiL gene expression in rich (Fig. 6a) and minimal media. This view was strengthened by finding that yeiL expression is significantly dependent on RpoS $\left(\sigma^{\mathrm{S}}\right)$, the stationary-phase sigma factor (Kolter et al., 1993), which is also essential for starvation survival (Lange \& Hengge-Aronis, 1991). The requirements for Lrp and IHF (especially in the absence of FNR) are consistent with their greater abundance in slow-growing or stationary-phase organisms (Landgraf et al., 1996; Goosen \& van de Putte, 1995). No rationale can be offered at present for the positive autoregulatory effect of YeiL on yeiL gene expression, nor for the aerobic repression by FNR, be it direct or indirect. 
However, the fact that expression of the $r p o S, \operatorname{lr} p$ and ihf genes is stimulated by ppGpp (Aviv et al., 1994; Lange et al., 1995) and that many genes induced by carbon, phosphorus and nitrogen starvation are regulated by the stringent response (Nyström, 1995; Rao et al., 1998), is consistent with YeiL being involved in the response to nutrient starvation.

Although the nitrogen-starvation-survival defect may not be a direct consequence of yeiL inactivation, it may be significant that yeiL is located within a cluster of genes concerned with nucleoside metabolism. Indeed, $y e i L$ and the adjacent yeiK gene, encoding a potential purine salvage pathway enzyme, are divergently transcribed from overlapping promoters, suggesting that YeiL might regulate yeiK expression as well as autoregulate its own synthesis. Salvage pathways recycle nucleosides and nucleobases for nucleic acid synthesis but these intermediates can also serve as carbon and nitrogen sources. It is therefore conceivable that YeiL might control expression of the salvage pathways or in some other way repress the recycling of nucleobases to nucleic acids and enhance their use as general nitrogen sources, during nitrogen-limited growth. Lack of YeiL might exacerbate the nitrogen deficiency and thus be responsible for the modest nitrogen-starvation-survival defect of the yeiL mutant. The toxic effects of excess YeiL might likewise be due (at least in part) to repression of the salvage pathways. There is no clear connection between the presence of potential iron-sulphur or disulphide-dithiol redox sensors in YeiL, and postexponential growth and nitrogen metabolism. Regulator defects often generate pleiotropic phenotypes and it is hoped that further studies will reveal the basis of the relatively diverse and subtle changes observed here. The curious and as yet unexplained fourfold stationaryphase activation/deactivation of overproduced apoaconitase A observed by Prodromou et al. (1991) may be related insofar as it indicates that iron-sulphur cluster assembly/disassembly is occurring when YeiL is being expressed and/or activated.

This work has laid a foundation for future investigations aimed at defining the precise role of the third member of the CRP family in E. coli. Further studies will be needed to elucidate exactly how extra YeiL enhances growth yield whereas excess YeiL is toxic, and also how YeiL regulates yeiL and yeiK gene expression. It will also be important to identify other potential members of the YeiL regulon and to find ways of stabilizing the free protein in order to define the nature of the DNA-binding form, the nucleotide sequence to which it binds, and the physiological signal that is recognized, as well as to establish whether the iron-sulphur cluster and disulphide-dithiol formation participate in DNA-binding or signal recognition.

\section{ACKNOWLEDGEMENTS}

We thank our colleagues, Drs P. J. Artymiuk and L. Cunningham, for advice and assistance with molecular graphics and primer extension analysis (respectively), Dr
A. J. G. Moir and Mr S. Thorpe (Krebs Institute Analytical Facilities) for N-terminal amino acid and nucleotide sequence analyses, and mass spectroscopy, and the BBSRC for an Advanced Fellowship (J.G.). The work was supported by a project grant from The Wellcome Trust (J.R.G.).

\section{REFERENCES}

Aiba, H., Adhya, S. \& de Crombrugghe, B. (1981). Evidence for two functional gal promoters in intact Escherichia coli cells. J Biol Chem 256, 11905-11910.

Artymiuk, P. J., Poirrette, A. R., Grindley, H. M., Rice, D. W. \& Willett, P. (1994). A graph-theoretic approach to the identification of three-dimensional patterns of amino acid side-chains in protein structures. J Mol Biol 243, 327-344.

Aviv, M., Giladi, H., Schreiber, G., Oppenheim, A. B. \& Glaser, G. (1994). Expression of the genes coding for the Escherichia coli integration host factor are controlled by growth phase, rpoS, ppGpp and by autoregulation. Mol Microbiol 14, 1021-1031.

Beinert, H. (1983). Semi-micro methods for analysis of labile sulfide and of labile sulfide plus sulfane sulfur in unusually stable iron sulfur proteins. Anal Biochem 131, 373-378.

Benson, D. E., Wisz, M. S., Liu, W. \& Hellinga, H. W. (1998). Construction of a novel redox protein by rational design: conversion of a disulfide bridge into a mononuclear iron-sulfur center. Biochemistry 37, 7070-7076.

Blattner, F. R., Plunkett, G., III, Bloch, C. A. \& 14 other authors (1997). The complete genome sequence of Escherichia coli K-12. Science 277, 1453-1470.

Busby, S. \& Ebright, R. H. (1997). Transcription activation at class II CAP-dependent promoters. Mol Microbiol 23, 853-859.

Busby, S. \& Kolb, A. (1996). The CAP modulon. In Regulation of Gene Expression in Escherichia coli, pp. 255-279. Edited by E. C. C. Lin \& S. A. Lynch. Austin, TX: R. G. Landes.

Cui, Y., Wang, Q., Stormo, G. D. \& Calvo, J. M. (1995). A consensus sequence for binding of Lrp to DNA. J Bacteriol 177, 4872-4880.

Cunningham, L., Gruer, M. J. \& Guest, J. R. (1997). Transcriptional regulation of the aconitase genes $(a c n A$ and $a c n B)$ of Escherichia coli. Microbiology 143, 3795-3805.

Davis, B. D., Luger, S. M. \& Tai, P. C. (1986). Role of ribosome degradation in the death of starved Escherichia coli cells. $J$ Bacteriol 166, 439-445.

Degano, M., Gopaul, D. N., Scapin, G., Schramm, V. L. \& Sacchettini, J. C. (1996). Three-dimensional structure of the inosine-uridine nucleoside $N$-ribohydrolase from Crithidia fasciculata. Biochemistry 35, 5971-5981.

Freundlich, M., Ramani, N., Mathew, E., Sirko, A. \& Tsui, P. (1992). The role of integration host factor in gene expression in Escherichia coli. Mol Microbiol 6, 2557-2563.

Gamer, J., Multhaup, G., Tomoyasu, T., McCarty, J. S., Râdiger, S., Schönfeld, H. J., Schirra, C., Bujard, H. \& Bukau, B. (1996). A cycle of binding and release of the DnaK, DnaJ and GrpE chaperones regulates activity of the Escherichia coli heat shock transcription factor $\sigma^{32}$. EMBO J 15, 607-617.

Goosen, N. \& van de Putte, P. (1995). The regulation of transcription initiation by integration host factor. Mol Microbiol 16, 1-7.

Gostick, D. O., Green, J., Gasson, M. J. \& Guest, J. R. (1997). Redox-mediated regulation by an FNR homologue. In International Anaerobic Metabolism and Regulation Workshop (Marseille), abstract A12.

Gostick, D. O., Green, J., Irvine, A. S., Gasson, M. J. \& Guest, J. R. 
(1998). A novel regulatory switch mediated by the FNR-like protein of Lactobacillus casei. Microbiology 144, 705-717.

Gostick, D. O., Griffin, H. G., Shearman, C. A., Scott, C., Green, J., Gasson, M. J. \& Guest, J. R. (1999). Two operons that encode FNR-like proteins in Lactococcus lactis. Mol Microbiol 31, 1523-1535.

Green, J., Sharrocks, A. D., Green, B., Geisow, M. \& Guest, J. R. (1993). Properties of FNR proteins substituted at each of the five cysteine residues. Mol Microbiol 8, 61-68.

Green, J., Bennett, B., Jordan, P., Ralph, E. T., Thomson, A. J. \& Guest, J. R. (1996). Reconstitution of the [4Fe-4S] cluster in FNR and demonstration of the aerobic-anaerobic transcription switch in vitro. Biochem J 316, 887-892.

Green, J., Anjum, M. F. \& Guest, J. R. (1997). Regulation of the $n d h$ gene of Escherichia coli by IHF and a novel regulator, Arr. Microbiology 143, 2865-2875.

Guest, J. R., Green, J., Irvine, A. S. \& Spiro, S. (1996). The FNR modulon and FNR regulated gene expression. In Regulation of Gene Expression in Escherichia coli, pp. 317-342. Edited by E. C. C. Lin \& S. A. Lynch. Austin, TX: R. G. Landes.

Holm, R. H. \& Ibers, J. A. (1977). Synthetic analogues of active sites of iron-sulfur proteins. In Iron-Sulfur Proteins III, pp. 205-281. Edited by W. Lovenberg. London: Academic Press.

Hurme, R., Berndt, K. D., Normark, S. J. \& Rhen, M. (1997). A proteinaceous gene regulatory thermometer in Salmonella. Cell 90, 55-64.

Khoroshilova, N., Popescu, C., Munck, E., Beinert, H. \& Kiley, P. J. (1997). Iron-sulfur cluster disassembly in the FNR protein of Escherichia coli by $\mathrm{O}_{2}$ : [4Fe-4S] to [2Fe-2S] conversion with loss of biological activity. Proc Natl Acad Sci US A 94, 6087-6092.

Kiley, P. J. \& Beinert, H. (1999). Oxygen sensing by the global regulator, FNR: the role of the iron-sulfur cluster. FEMS Microbiol Rev 22, 341-352.

Kolter, R., Siegele, D. A. \& Tormo, A. (1993). The stationary-phase of the bacterial life cycle. Annu Rev Microbiol 47, 855-874.

Kraulis, P. J. (1991). MOLSCRIPT: a program to produce both detailed and schematic plots of protein structures. J Appl Cryst 24, 946-950.

Kushner, S. R., Nagaishi, H., Templin, A. \& Clark, A. J. (1971). Genetic recombination in Escherichia coli: the role of exonuclease I. Proc Natl Acad Sci US A 68, 824-827.

Landgraf, J. R., Wu, J. \& Calvo, J. M. (1996). Effects of nutrition and growth rate on Lrp levels in Escherichia coli. J Bacteriol 178, 6930-6936.

Lange, R. \& Hengge-Aronis, R. (1991). Identification of a central regulator of stationary-phase gene expression in Escherichia coli. Mol Microbiol 5, 49-59.

Lange, R., Fischer, D. \& Hengge-Aronis, R. (1995). Identification of transcriptional start sites and the role of ppGpp in the expression of $r p o S$, the structural gene for the $\sigma^{\mathrm{S}}$ subunit of RNA polymerase in Escherichia coli. J Bacteriol 177, 4676-4680.

Lazazzera, B. A., Beinert, H., Khoroshilova, N., Kennedy, M. C. \& Kiley, P. J. (1996). DNA binding and dimerization of the Fe-Scontaining FNR protein from Escherichia coli are regulated by oxygen. J Biol Chem 271, 2762-2768.

Li, B., Wing, H., Lee, D., Wu, H. \& Busby, S. (1998). Transcription activation by Escherichia coli FNR protein: similarities to, and differences from, the CRP paradigm. Nucleic Acid Res 26, 2075-2081.

Marinus, M. G. \& Morris, M. R. (1973). Isolation of deoxy- ribonucleic acid methylase mutants of Escherichia coli K-12. J Bacteriol 114, 1143-1150.

Martinez, E., Bartolomé, B. \& Delacruz, F. (1988). pACYC184derived cloning vectors containing the multiple cloning site and lacz $\alpha$ reporter gene of pUC8/9 and pUC18/19 plasmids. Gene 68, 159-162.

Miller, J. H. (1972). Assay of $\beta$-galactosidase. In Experiments in Molecular Genetics, pp. 352-355. Cold Spring Harbor, NY : Cold Spring Harbor Laboratory.

Nyström, T. (1995). Glucose starvation stimulon of Escherichia coli: role of integration host factor in starvation survival and growth phase-dependent protein synthesis. J Bacteriol 177, 5707-5710.

Oden, K. L., De Veaux, L. C., Vibat, C. R. T., Cronan, J. E. Jr \& Gennis, R. B. (1990). Genomic replacement in Escherichia coli K12 using covalently closed circular plasmid DNA. Gene 96, 29-36.

Prodromou, C., Haynes, M. J. \& Guest, J. R. (1991). The aconitase of Escherichia coli: purification of the enzyme and molecular cloning and map location of the gene $(a c n)$. J Gen Microbiol 137, 2505-2515.

Rao, N. N., Liu, S. J. \& Kornberg, A. (1998). Inorganic polyphosphate in Escherichia coli: the phosphate regulon and the stringent response. J Bacteriol 180, 2186-2193.

Robbins, A. H. \& Stout, C. D. (1989). Structure of activated aconitase: formation of the [4Fe-4S] cluster in the crystal. Proc Natl Acad Sci U S A 86, 3639-3643.

Sambrook, J., Fritsch, E. F. \& Maniatis, T. (1989). Molecular Cloning: a Laboratory Manual. 2nd edn. Cold Spring Harbor, NY: Cold Spring Harbor Laboratory.

Schultz, S. C., Shields, G. C. \& Steitz, T. A. (1991). Crystalstructure of a CAP-DNA complex - the DNA is bent by $90^{\circ}$. Science 253, 1001-1007.

Simons, R. W., Houman, F. \& Kleckner, N. (1987). Improved single and multicopy lac-based cloning vectors for protein and operon fusions. Gene 53, 85-96.

Spiro, S. (1994). The FNR family of transcriptional regulators. Antonie Leeuwenhoek 66, 23-36.

Staden, R. (1982). An interactive graphics package for comparing and aligning nucleic acid and amino acid sequences. Nucleic Acid Res 10, 2951-2961.

Straus, D., Walter, W. \& Gross, C. A. (1990). DnaK, DnaJ, and GrpE heat shock proteins negatively regulate heat shock gene expression by controlling the synthesis and stability of $\sigma^{32}$. Genes Dev 4, 2202-2209.

Thannhauser, T. W., Konishi, Y. \& Scheraga, H. A. (1987). Analysis for disulfide bonds in peptides and proteins. Methods Enzymol 143, 115-119.

Thelander, L. (1973). Physicochemical characterization of ribonucleoside diphosphate reductase from Escherichia coli. J Biol Chem 248, 4591-4601.

VanBogelen, R. A. \& Neidhardt, F. C. (1990). Ribosomes as sensors of heat and cold shock in Escherichia coli. Proc Natl Acad Sci US A 87, 5589-5593.

Vogel, H. \& Bonner, D. M. (1956). A convenient growth medium for Escherichia coli and some other micro-organisms. Microb Genet Bull 13, 43-44.

Vollack, K. U., Hartig, E., Korner, H. \& Zumpft, W. G. (1999). Multiple transcription factors of the FNR family in denitrifying Pseudomonas stutzeri: characterization of four fnr-like genes, regulatory responses and cognate metabolic processes. Mol Microbiol 31, 1681-1694. 
Woodland, M. P. \& Dalton, H. (1984). Purification and characterization of component A of the methane monooxygenase from Methylococcus capsulatus (Bath). J Biol Chem 259, 53-59.

Wu, G., Cruz-Ramos, H., Hill, S., Green, J., Sawers, G. \& Poole, R. K. (2000). Regulation of cytochrome $b d$ expression in the obligate aerobe Azotobacter vinelandii by CydR (Fnr) : sensitivity to oxygen, reactive oxygen and nitric oxide. J Biol Chem 275, $4679-4686$.

Received 22 June 2000; revised 17 August 2000; accepted 22 August 2000. 